\title{
Vesico-Salpingo Fistula Masquerading as Hydrosalpinx with Neurogenic Bladder - An Interesting Case Report
}

\author{
Senthil Kumar Thiagarajan ${ }^{1}$ \\ ${ }^{1}$ Department of Urology, SRM Medical College Hospital and Research Centre, SRM Institute of Science and Technology, \\ SRM Nagar, Kattankulathur, Kanchipuram, Chennai, Tamil Nadu, India.
}

\section{INTRODUCTION}

A fistula is an abnormal connection between two luminal structures of different epithelium. The majority of urological fistulas in developed countries are consequences of iatrogenic injury most commonly laparoscopic hysterectomies, or from radiotherapy in the treatment of pelvic cancers. ${ }^{1}$ Contrary to this, most obstetric fistulas in developing countries result from obstructed labour during childbirth. ${ }^{2}$ Common factors that contribute to obstructed labour in developing countries are delayed presentation after trial labour at home, cephalopelvic disproportion and poor nutrition.

Due to prolonged compression by head on the pelvic tissues there happens ischemic necrosis of vagina, bladder neck, and urethra ${ }^{3}$ called obstructed labour complex. Necrosis and fibrotic healing lead to fistula formation with adjacent structures. The vesicovaginal fistula was the most frequent one (78\%) and the common site involved was trigone (51\%) and based on the level it could be a high or low fistula. Others are vesicouterine fistula, vesicourethral fistula, vesicoureteral fistula and rarely vesico-salpingo fistula. During the acute phase of fistula, tissue oedema, hypovascularity, infection, and nonviable tissue hinder proper tissue healing and hence delayed repair is done after 3 months.

Recent literature advises early repair for simple fistulas to reduce patient morbidity and delayed repair of complex fistula, multiple fistulas, infected fistulas, post-radiotherapy, fistula due to foreign bodies, immunocompromised patients, hypoproteinaemia patients, urosepsis patients. ${ }^{4}$ Fistula repair is preceded by contrast evaluation of ureter and bladder by CT -IVU and cystogram or MRI followed by cystoscopy or retrograde pyelography.

Apart from fistula closure, bilateral ureteric implantation may be needed if ureters are close to the fistula. ${ }^{5}$ Abdominal hysterectomy is done in uterovesical fistulas. Huge fistulas close to the bladder neck cannot be repaired without compromising continence hence bladder neck closure is done with the Mitrofanoff procedure. ${ }^{6}$ A vesico-salpingo fistula is an abnormal epithelial-lined communication between the urinary bladder and the fallopian tube. This rare type of urogenital fistula has only 7 previously published cases in the literature. . $^{70}$

\section{PRESENTATION OF CASE}

A 32-year-old para - 2, live - 1, and death - 1 female presented with lower abdominal pain and difficulty in passing urine and constipation for five years. She had a past history of intra-uterine death at 30 weeks of gestation in 2015 and underwent a caesarean section.
Corresponding Author:

Dr. T. Senthilkumar,

Professor,

Department of Urology.

SRM Medical College Hospital and

Research Centre, Kattankulathur, 603203,

Kanchipuram, Chennai, TN, India.

E-mail: drsenku12101978@gmail.com

DOI: $10.14260 /$ jemds/2021/600

How to Cite This Article:

Thiagarajan SK. Vesico-salpingo fistula masquerading as hydrosalpinx with neurogenic bladder - an interesting case report. J Evolution Med Dent Sci 2021;10(34):2942-2944, DOI: $10.14260 /$ jemds/2021/600

Submission 20-05-2021,

Peer Review 13-07-2021,

Acceptance 20-07-2021,

Published 23-08-2021.

Copyright (C) 2021 Senthil Kumar Thiagarajan. This is an open access article distributed under Creative Commons Attribution License [Attribution 4.0 International (CC BY 4.0)] 


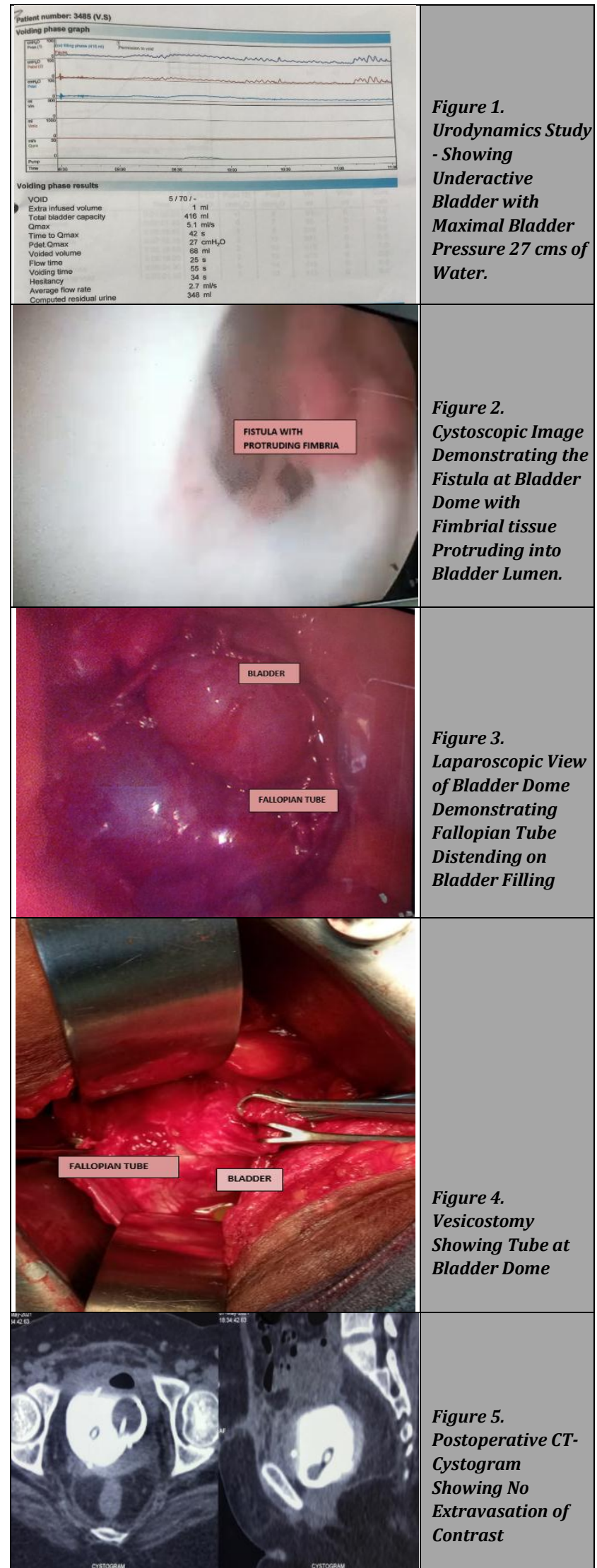

The patient had a postpartum haemorrhage and went for a shock and was referred to a tertiary centre where relaparotomy was done and due to continuous bleeding partial hysterectomy was done leaving behind the tubes, ovaries and cervix. Postoperatively she had an acute kidney infection, sepsis, acute respiratory distress syndrome (ARDS). She was managed in the intensive renal care unit and recovered. Currently, on examination, she was moderately built and abdomen examination showed mild supra-pubic tenderness. The patient was worked up by a gynaecologist and urologist. Ultrasound showed bilateral hydrosalpinx. Urodynamics was done for urinary obstruction and showed peak flow velocity of $5 \mathrm{ml} / \mathrm{sec}$ and P - det at Qmax was 27 cms of water suggesting? Neurogenic bladder (Figure 1). All blood parameters were within the normal limits. The patient was planned for laparoscopic salpingectomy with diagnostic cystoscopy.

\section{PATHOLOGICAL DISCUSSION}

The fallopian tube showed chronic fibrotic changes with squamous metaplasia. No evidence of dysplastic changes in bladder and tubal specimens were sent.

\section{DISCUSSION OF MANAGEMENT}

The patient was worked up with an ultrasound which revealed a tubular structure adjacent to the bladder probably hydrosalpinx. The urodynamic study showed underactive bladder. Hence taken up for laparoscopic salpingectomy with diagnostic cystoscopy. Diagnostic cystoscopy showed a fistula of size $1 \mathrm{~cm}$ at the dome of the bladder and fimbrial tissue was seen protruding into the bladder (Figure 2). Cystoscope had just entered the fistula tract. Simultaneously laparoscopic ports were inserted, and it showed fallopian tubes adherent to the bladder and distending on bladder filling with cystoscopy (Figure - 3).

Since anatomy could not be delineated due to dense adhesions of the bowel, laparoscopy was converted to open surgery. Anterior vertical cystotomy was done up to fistula (Figure 4). Adherent bowel and omentum released. Both ovaries with the cervix were present. The fistula tract was seen at the bladder dome, and it was joined with the right fallopian tube enclosed by a fibrous sac. Sac was dissected and fallopian tube and fistulas were excised. Bladder flaps were raised from the adherent remnant cervix and were closed in two layers. Suprapubic cystostomy catheter was placed. Postoperative period was uneventful.

Drain tube removed after four days and the patient was sent home the next day. A follow-up CT - cystogram (Figure 5) was done on the 12th postoperative day and had shown no contrast extravasation. Suprapubic catheter was removed on post-operative day 14. Urethral Foleys removed on postoperative day 18 . The patient complained of reduced bladder sensation and had post-void residual urine of $50 \mathrm{ml}$ and hence was started on bethanechol tablet $25 \mathrm{mg}$ twice daily. Patient was passing urine normally and follow up ultrasound showed $10 \mathrm{ml}$ postvoid residual urine.

\section{DISCUSSION}

Torrential bleeding during hysterectomy is managed by clamping the uterine vessels. Undue usage of cautery near bladder wall or passage of uterine suture through bladder leads to necrosis of bladder wall leading to the formation of fistulous communication with adjacent structures like 
fallopian tube, vagina, and cervix. Usually, part of one fallopian tube and ovary will be preserved in young patients undergoing hysterectomy for unavoidable reasons. Here communication has occurred between the fallopian tube and the bladder. The first vesico-salpingo fistula in the literature was diagnosed by Rozin in 1954 while evaluating a 24 - year old woman for sterility of 5 years duration. ${ }^{8}$ More than 60 years have passed since then, and there have been only four additional vesico-salpingo fistula case reports published in the literature. Previously reported vesico-salpingo fistulas have had aetiologies which were either unknown, ${ }^{8}$ secondary to a vaginal hysterectomy, ${ }^{9}$ or from a tubo-ovarian abscess. ${ }^{7}$ In this case the cause was previous caesarean section with postpartum haemorrhage. Vesico-salpingo fistulas may present with signs and symptoms, which include sterility, ${ }^{7}$ lower abdominal pain, ${ }^{7,10}$ dysuria, ${ }^{9}$ fever, ${ }^{7}$ recurrent urinary tract infections,, 10 and vaginal urine leakage. The delay in diagnosis occurs in vesicosalpingo fistula when compared to other gynaecological fistulas since there is no urinary leak and the symptoms are vague. Early fever that might happen due to tubal abscess is missed easily and masked by modern antibiotics. A high degree of suspicion, detailed history and physical examination should be done. Apart from basic ultrasound which is non-specific in such rare fistulas, contrast imaging by CT cystography or MRI or diagnostic cystoscopy can only diagnose this fistula.

It can also exclude the presence of multiple concurrent fistulas, such as urethra - vaginal, vesico-cervical, vesicouterine, vesico-ureteral, or vesico-salpingo fistulas. Two of the 4 reported cases of vesicosalpingo fistulas were treated with salpingo-oophorectomy,, 910 one was treated with fistulectomy and salpingostomy, ${ }^{8}$ and one was treated by removing an intrauterine contraceptive device, which was suspected as the inciting cause of a tubo-ovarian abscess, and placement of a Foley catheter drainage with parenteral antibiotics for 11 days. $^{7}$ Conservative non-operative management of a vesico-salpingo fistula with Foley catheter drainage, fistula tract irrigation, and antibiotics is only temporarily beneficial.9,10 In patients with multiple fistulas, recurrent fistulas, large fistulas, uterovesical fistulas or postradiotherapy fistulas tissue interposition should be done. Commonly omental flap, ${ }^{11}$ peritoneal flaps, gracilis flap are used. Postoperatively close monitoring of the patient is done for catheter block and any clots in the bladder may disrupt the anastomosis. Proper nutrition, hydration, and antibiotics are crucial in the healing process. Bladder relaxants and a long-term maintenance dose of antibiotics are given postoperatively for 2 weeks to ensure sterile urine and wound healing. After 2 weeks a cystogram is done for assessing healing and if bladder contour is normal suprapubic catheter is removed and strapping is done. After 3 days urethral foley catheter was removed and voiding assessed. Post-op ultrasound was done on follow up to check the completeness of bladder emptying.

\section{FINAL DIAGNOSIS}

This is a case of vesico-salpingo fistula probably due to missed bladder injury during a partial hysterectomy with underactive bladder. Long term efflux of urine into fallopian tubes causing bladder dysfunction leads to the underactive bladder. This is a rare complication of hysterectomy and $7^{\text {th }}$ case to be reported as per the literature.

\section{CONCLUSIONS}

High suspicion is needed in post-hysterectomy or post caesarean patients' complaining of voiding dysfunction and workup is needed to identify this rare complication like vesico-salpingo fistula and other uncommon fistulas.

Financial or other competing interests: None.

Disclosure forms provided by the authors are available with the full text of this article at jemds.com.

\section{REFERENCES}

[1] Langkilde NC, Pless TK, Lundbeck F, et al. Surgical repair of vesicovaginal fistulae-a ten-year retrospective study. Scand J Urol Nephrol 1999;33(2):100-3.

[2] Lewis G. World Health Organization, Department of Making Pregnancy Safer. Obstetric fistula: guiding principles for clinical management and programme development. Geneva: World Health Organization, 2006.

[3] Ekanem EI, Ekanem AD, Ekabua JE, et al. Review of obstetrics genito - urinary fistulae in the University of Calabar Teaching Hospital Calabar, Nigeria. Niger J Clin Pract 2010;13(3):326-30.

[4] Singh 0, Gupta SS, Mathur RK. Urogenital fistulas in women: 5-year experience at a single center. Urol J 2010;7(1):35-9.

[5] Agrawal V, Kucherov V, Bendana E, et al. Robot - assisted laparoscopic repair of vesicovaginal fistula: a singlecenter experience. Urology 2015;86(2):276-82.

[6] Priyadarshi V, Singh JP, Bera MK, et al. Genitourinary fistula: an Indian perspective. J Obstet Gynaecol India 2016;66(3):180-4.

[7] London AM, Burkman RT. Tuboovarian abscess with associated rupture and fistula formation into the urinary bladder: report of two cases. Am J Obstet Gynecol 1979;135(8):1113-4

[8] Rozin S. The diagnosis of tubointestinal and tubovesical fistulas by hysterosalpingography. Am J Obstet Gynecol 1954;68(6):1525-34.

[9] Stewart DW, Gianis TJ, Bell TE. Salpingo-vesical fistula. Rare and unusual complication of vaginal hysterectomy. Urology 1990;36(1):66-7.

[10] Turner BI, Ekbladh L, Edson M. Vesicosalpingovaginal fistula. Urology 1976;8(1):49-50.

[11] Sapmaz E, Celik H, Semerciöz A. Omental graft use in Youssef syndrome. Eur J Obstet Gynecol Reprod Biol 2003;109(1):92-6. 